\title{
Asymmetrical heat transfer through composites of water and aqueous solutions in the presence of the density maximum
}

\author{
M.F. Cawley*, P.A. Mooney, P. O’Connor \\ Department of Experimental Physics, National University of Ireland, Maynooth, County Kildare, Ireland
}

Received 4 December 2006

Available online 5 June 2007

\begin{abstract}
A device is described through which heat flows at different rates depending on the orientation of the temperature gradient. The device consists of two cubic enclosures side by side, one of which is filled with pure water with a temperature of maximum density of $4{ }^{\circ} \mathrm{C}$, and the other which contains a saline solution with a temperature of maximum density of $2{ }^{\circ} \mathrm{C}$. A temperature gradient, which spans both of these temperatures of maximum density, is applied horizontally across the composite system, resulting in different rates of heat transfer through the device depending on the gradient direction. Experiments performed with a $12 \times 6 \times 6$ cm container yield heat transfer rates of $0.55 \mathrm{~W}$ and $0.19 \mathrm{~W}$ depending on the direction of the temperature gradient, resulting in a rectification factor of $65.4 \%$. Asymmetrical heat transfer rates are also found in composite systems of water and solids when the temperature gradient spans the temperature of maximum density of the water. Results from computational fluid dynamics confirm the experimental results, and are used to investigate the influence of such parameters as temperature gradient and container aspect ratio on the rectification factor.
\end{abstract}

(C) 2007 Elsevier Ltd. All rights reserved.

Keywords: Water; Water solution; Density maximum; Thermal rectification; Heat diode; Heat rectifier; Asymmetrical heat transfer

\section{Introduction}

Heat transfer across a region is asymmetric if the absolute magnitude of the heat flow changes when the temperature gradient is reversed. An example of such a situation is that of a vertical temperature gradient applied across a region of fluid. For simple Newtonian fluids, heat transfer via both conduction and convection will take place if the temperature decreases with height (i.e. warmer fluid below cooler fluid) whereas only conduction will take place if the temperature increases with height (warmer fluid resting above cooler fluid), thus leading to a decrease in the magnitude of the heat transfer. Asymmetrical heat transfer may also be present in non-uniform or composite systems which are not invariant to $180^{\circ}$ rotation; in such instances, the asymmetry of the heat flow becomes apparent if either

\footnotetext{
${ }^{*}$ Corresponding author. Fax: +35317083313.

E-mail address: michael.cawley@nuim.ie (M.F. Cawley).
}

the temperature gradient is reversed or if the system is rotated (while holding the temperature gradient fixed). An example of this situation would be a combination of a region of phase change material (PCM) adjacent to a region which does not undergo a phase change within the temperature range in question. For one orientation of the system the PCM would be in one state (e.g. solid) whereas for the other orientation it would undergo a phase change to a different state (e.g. liquid), with different heat conductance properties. Once again this results in a combination of conduction and convection in one mode, and conduction only in the other mode. Heat transfer asymmetry is also a feature of green houses and the so-called green-house effect in planetary systems. In such cases, however, the temperature gradient is not strictly reversed; the effective magnitudes of the hot $\left(T_{\mathrm{h}}\right)$ and cold $\left(T_{\mathrm{c}}\right)$ temperatures which impose the gradient are not the same between day and night.

In this work, the following restrictive conditions for heat transfer asymmetry will be assumed: 


\section{Nomenclature}

A cross-section area $\left(\mathrm{m}^{2}\right)$

$c_{0} \quad$ coefficient, parabolic density function for water $\left(\mathrm{kg} \mathrm{m}^{-3}\right)$

$c_{1} \quad$ coefficient, parabolic density function for water $\left(\mathrm{kg} \mathrm{m}^{-3}{ }^{\circ} \mathrm{C}^{-1}\right)$

$c_{2} \quad$ coefficient, parabolic density function for water $\left(\mathrm{kg} \mathrm{m}^{-3}{ }^{\circ} \mathrm{C}^{-2}\right)$

$C_{p} \quad$ specific heat capacity (constant pressure) $\left(\mathrm{J} \mathrm{K}^{-1} \mathrm{~kg}^{-1}\right)$

d depth (m)

g acceleration due to local gravity $\left(\mathrm{m} \mathrm{s}^{-2}\right)$

$h \quad$ height $(\mathrm{m})$

$H \quad$ rate of heat transfer $(\mathrm{W}) ; H=\mathrm{d} Q / \mathrm{d} t$

$H_{\mathrm{H}} \quad$ high rate of heat transfer $(\mathrm{W})$

$H_{\mathrm{L}} \quad$ low rate of heat transfer $(\mathrm{W})$

$k \quad$ thermal conductivity $\left(\mathrm{W} \mathrm{m}^{-1} \mathrm{~K}^{-1}\right)$

$p \quad$ pressure $(\mathrm{Pa})$

$r \quad$ rectification factor; $r=\left(H_{\mathrm{H}}-H_{\mathrm{L}}\right) / H_{\mathrm{H}}$

$t$

time (s)
$T_{\rho \max }$ temperature of density maximum, pure water $\left({ }^{\circ} \mathrm{C}\right)$

$T_{\rho \text { max,sol }}$ temperature of density maximum, aqueous solution $\left({ }^{\circ} \mathrm{C}\right)$

$T_{\mathrm{h}} \quad$ temperature of hot wall $\left({ }^{\circ} \mathrm{C}\right)$

$T_{\mathrm{c}} \quad$ temperature of cold wall $\left({ }^{\circ} \mathrm{C}\right)$

$T_{\mathrm{m}, \mathrm{h}} \quad$ monitor temperature, hot wall $\left({ }^{\circ} \mathrm{C}\right)$

$T_{\mathrm{m}, \mathrm{c}}$ monitor temperature, cold wall $\left({ }^{\circ} \mathrm{C}\right)$

$T_{\mathrm{L}} \quad$ temperature of left wall $\left({ }^{\circ} \mathrm{C}\right)$

$T_{\mathrm{R}} \quad$ temperature of right wall $\left({ }^{\circ} \mathrm{C}\right)$

$T_{\mathrm{m}, \mathrm{L}} \quad$ monitor temperature, left wall $\left({ }^{\circ} \mathrm{C}\right)$

$T_{\mathrm{m}, \mathrm{R}} \quad$ monitor temperature, right wall $\left({ }^{\circ} \mathrm{C}\right)$

$(u, v) \quad$ velocity components $\left(\mathrm{m} \mathrm{s}^{-1}, \mathrm{~m} \mathrm{~s}^{-1}\right)$

$\mathbf{v} \quad$ velocity vector $\left(\mathrm{m} \mathrm{s}^{-1}\right)$

$w \quad$ width (m)

$\Delta x \quad$ width of reference material $(\mathrm{m})$

$\mu \quad$ dynamic viscosity $\left(\mathrm{kg} \mathrm{m}^{-1} \mathrm{~s}^{-1}\right)$

$\rho \quad$ density $\left(\mathrm{kg} \mathrm{m}^{-3}\right)$ (i) the values of $T_{\mathrm{h}}$ and $T_{\mathrm{c}}$ must be the same for both orientations of the system or of the temperature gradient (excludes green-house effects),

(ii) the system has reached steady-state (excludes transient effects).

It will be shown that heat flow asymmetry is possible in water in the vicinity of the temperature of maximum density. It has previously been reported [1,2] that the rate of horizontal heat transfer through water decreases in the vicinity of the temperature of maximum density. A horizontal temperature gradient across a rectangular region of fluid will normally give rise to a single recirculation convective cell, with fluid rising at the hot wall (at temperature $T_{\mathrm{h}}$ ) and descending at the cold wall (at temperature $T_{\mathrm{c}}$ ). This single-cell convective pattern changes to a double cell if the temperature gradient encompasses the temperature of maximum density. A symmetric double-cell configuration will result if the temperature of maximum density is midway between $T_{\mathrm{h}}$ and $T_{\mathrm{c}}$, with fluid rising at both the hot and cold walls, and descending in the centre of the enclosure. The resulting reduction in the rate of heat transfer has been attributed to the insulating nature of this double-cell configuration [1]: warmer fluid rising at the hot wall is prevented from reaching the cold wall by the presence of the second convective cell - the effect is similar to placing a conductive vertical barrier in the centre of the chamber. However, in addition to the insulating contribution of the double-cell configuration, there is also the consideration of the reduction in buoyancy of the water due to the flattening of the density state function (density as a function of temperature) in the vicinity of the density extremum. Both of these effects (insulation, buoyancy reduction) may be exploited to reduce the rate of heat transfer in water and its solutions. A simple arrangement will be described which exploits these effects in a composite system of pure water and a saline solution to give rise to heat flow asymmetry. Such asymmetry is also possible in composite systems of water and solids.

A number of devices which exhibit some degree of thermal rectification have been previously tested $[3,4,20]$ or proposed [5-9]. The performance of the water-based thermal rectifier described in this work will be discussed in the context of these other devices in Section 5.

\section{Experimental apparatus and procedures}

The system used to obtain the experimental results is a modified version of that described in previous publications $[10,11]$. In a typical experiment, a horizontal temperature difference is maintained across a region consisting of a test chamber sandwiched between two blocks of solid reference material (Perspex) by circulating coolant through coils in side chambers (Fig. 1). Thermistors embedded in metal plates are placed on both sides of the reference materials to measure the rate of heat transfer (Section 2.1). Each side chamber contains two copper coils, one of which is linked to a bank of coils within the freezer compartment of the refrigerator unit (temperature $\sim-30{ }^{\circ} \mathrm{C}$ ), and the other to a coil located in a thermal reservoir which is maintained at a temperature of $\sim 16{ }^{\circ} \mathrm{C}$ (located within the main refrigerator compartment; a heater in this reservoir can be used to raise its temperature as required). The temperature of the side chamber is controlled via the pumps which activate these heat exchangers. The coolant surrounding the coils within the side chamber is circulated using a miniature 


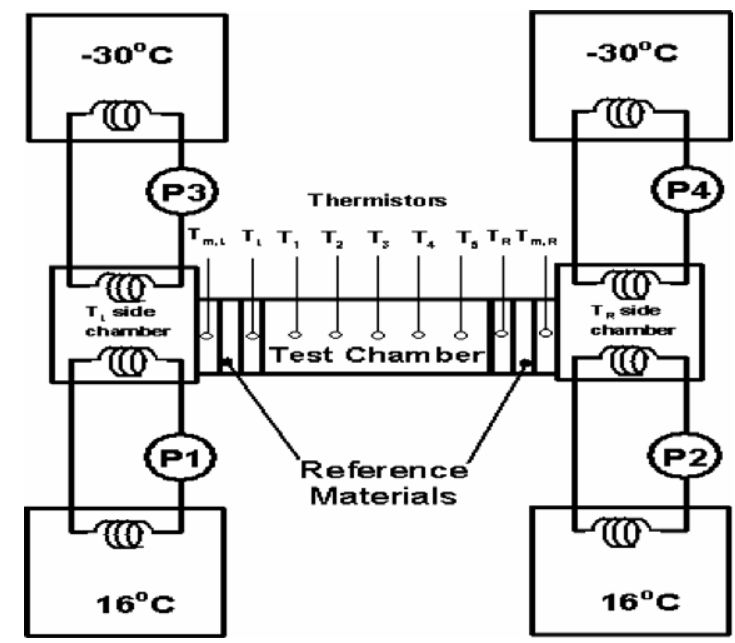

Fig. 1. Schematic diagram of the apparatus. P1 to P4 are pumps under computer control.

pump to maintain a uniform temperature along the side in contact with the test region. The test chamber had internal dimensions of $6 \mathrm{~cm} \times 6 \mathrm{~cm}$ (cross-section) and length $12 \mathrm{~cm}$, and was constructed from $6 \mathrm{~mm}$ Perspex with $6 \mathrm{~mm}$ Aluminium end-walls. Thermistors located throughout the system are calibrated to $0.1^{\circ} \mathrm{C}$ and are interfaced to a computer which controls the data acquisition system. Five thermistors are arranged in a horizontal line along the centre of the test chamber, at distances of $2 \mathrm{~cm}, 4 \mathrm{~cm}$, $6 \mathrm{~cm}, 8 \mathrm{~cm}$ and $10 \mathrm{~cm}$ relative to the left wall (during testing of the water and saline solution composite, which is discussed in Section 3.2, the middle thermistor $T_{3}$ located at the $6 \mathrm{~cm}$ position is removed to permit insertion of an aluminium partition in the centre of the test chamber). Two different experimental procedures are used, depending on the nature of the investigation being carried out. These procedures will be described in Sections 2.2 and 2.3, following a description of the method used to measure the rate of heat transfer.

\subsection{Measurement of rate of heat transfer}

A modified version of the longitudinal comparative cutbar method, normally used to determine thermal conductivities of solids, has been used to measure the rate of heat flow through the test region $[12,13]$. Solid reference materials of known thermal conductivity are placed on both sides of the test region, with thermistors embedded in the metal plates on both sides of each reference material (Fig. 1). The temperatures of the two side chambers are adjusted until the desired values of $T_{\mathrm{h}}$ and $T_{\mathrm{c}}$ are obtained on either side of the test region. Due to the presence of the solid reference materials $\left(1.25 \mathrm{~mm}\right.$ Perspex; $\left.k=0.19 \mathrm{~W} \mathrm{~m}^{-1} \mathrm{~K}^{-1}\right)$ the actual temperatures of the side chambers (and thus the temperatures at the monitoring points $T_{\mathrm{m}, \mathrm{h}}$ and $T_{\mathrm{m}, \mathrm{c}}$ ) will differ from $T_{\mathrm{h}}$ and $T_{\mathrm{c}}$ if the rate of heat flow is non-zero. If it is assumed that the heat flowing through each element of the system (hot-side reference material, test region, cold- side reference material) is the same under steady-state conditions, then the temperature drop registered across each reference material may be used to determine the rate of heat flowing through the test region:

$H_{\text {perspex }}=\frac{k_{\mathrm{p}} A\left(T_{\mathrm{m}, \mathrm{h}}-T_{\mathrm{h}}\right)}{\Delta x}$
$H_{\text {perspex }}=\frac{k_{\mathrm{p}} A\left(T_{\mathrm{c}}-T_{\mathrm{m}, \mathrm{c}}\right)}{\Delta x}$

where $k_{\mathrm{p}}$ is $0.19 \mathrm{~W} \mathrm{~m}^{-1} \mathrm{~K}^{-1}$ (Perspex), $A$ is the cross-section area of the test region and the Perspex reference material $\left(0.06 \times 0.06 \mathrm{~m}^{2}\right)$, and $\Delta x$ is the width of the Perspex regions $(1.25 \mathrm{~mm})$. Any difference in the heat flow rates across the two reference materials under steady-state conditions would indicate possible heat gain or loss within the test region. This is reduced by surrounding the test region with approximately $5 \mathrm{~cm}$ thickness of expanded polystyrene $\left(k=0.08 \mathrm{~W} \mathrm{~m}^{-1} \mathrm{~K}^{-1}\right)$.

Under non-steady-state conditions, such as the controlled cooling procedure described in Section 2.2, it is not expected that the heat flow rate will be equal across both reference materials. If the test sample is being gradually cooled over time, there will be two components to the heat flowing through the cold reference material: the heat flow due to the temperature gradient, and the heat extracted from the test sample as it is cooled. Thus, the measured heat flow rate on the cold side of the test region will be higher than that registered on the hot side of the sample. This imbalance is evident in the experimental results (Figs. 2 and 3). Conversely, if the test region is being gradually heated, the measured heat flow rate on the cold side will be less than that registered on the hot side of the test chamber.

To validate the cut-bar method, the test chamber was replaced by a solid of know thermal conductivity (typically $5 \mathrm{~mm}$ Perspex with the same cross-section area as the test

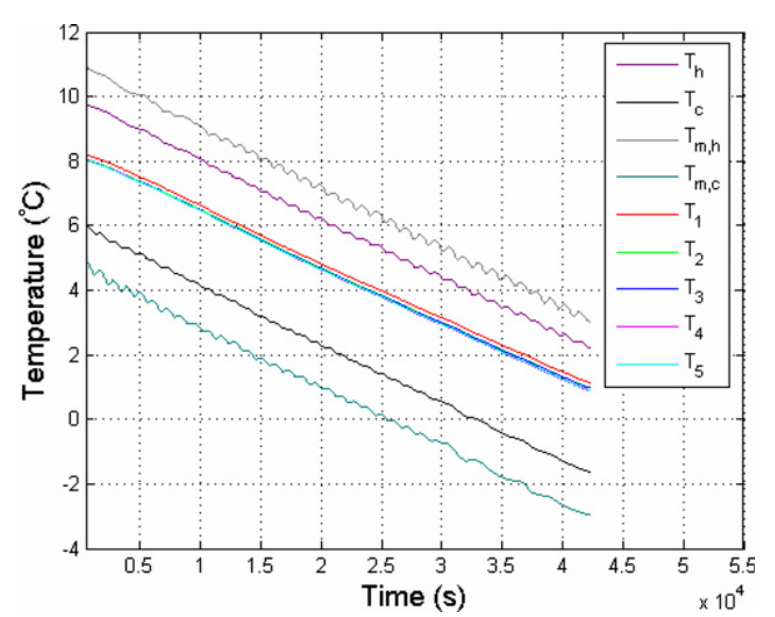

Fig. 2. Results from a controlled cooling experiment on ethanol. The curves above and below the closely clustered thermistor profiles are the $T_{\mathrm{h}}$ and $T_{\mathrm{c}}$ values, which are gradually reduced from $10^{\circ} \mathrm{C}$ and $6{ }^{\circ} \mathrm{C}$ to $2{ }^{\circ} \mathrm{C}$ and $-2{ }^{\circ} \mathrm{C}$ during the experiment. The uppermost curve is the $T_{\mathrm{m}, \mathrm{h}}$ profile and the lowest curve is the $T_{\mathrm{m}, \mathrm{c}}$ profile; these are used to determine the rate of heat flow through the test region. 


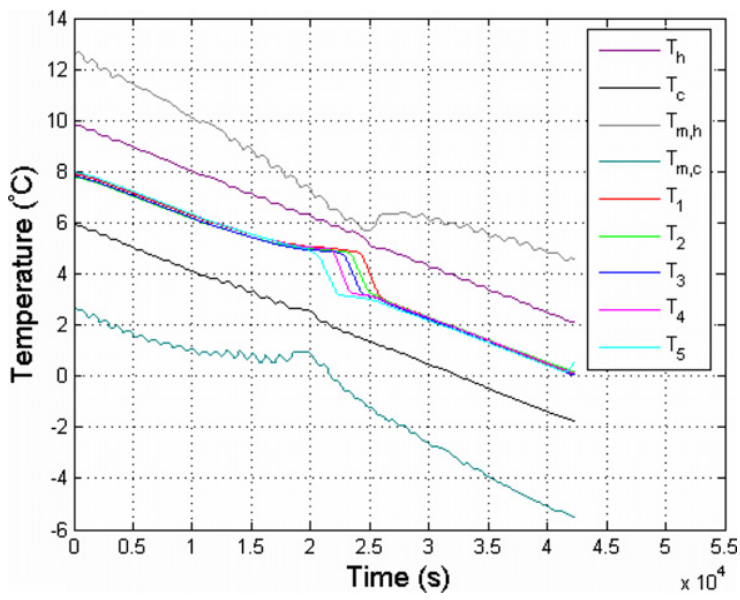

Fig. 3. Results from a controlled cooling experiment on water. The ordering of the curves is the same as in Fig. 2. The dispersion of the thermistor curves centred on $4{ }^{\circ} \mathrm{C}$ arises due to the formation of the double convective cell associated with the density anomaly. The dip in the $T_{\mathrm{m}, \mathrm{h}}$ curve and the peak in the $T_{\mathrm{m}, \mathrm{c}}$ curve are caused by the reduction in the heat flow through the test region in the vicinity of the density anomaly.

chamber), and the temperature drop across the hot-side and cold-side reference materials were checked against predictions for the known rate of heat flow under such circumstances. This procedure does not address the problem of non-isothermal conditions which are expected to prevail at the vertical walls of the test chamber when working with convecting fluids. It is found in practice, however, that there is good agreement between the rates of heat transfer as measured by the cut-bar method and those predicted from computational fluid dynamics (Section 4). Uncertainties in the heat transfer rates were estimated to be of the order of $5 \%$, assuming an uncertainty in temperature measurement of $0.1{ }^{\circ} \mathrm{C}$.

\subsection{Controlled cooling experiments}

In this procedure, a constant temperature difference is maintained across the test sample (usually $4{ }^{\circ} \mathrm{C}$ ) but both $T_{\mathrm{h}}$ and $T_{\mathrm{c}}$ are decremented by $0.1^{\circ} \mathrm{C}$ every $9 \mathrm{~min}$ in order to measure the change in the rate of heat transfer across the sample as a function of absolute temperature. Such 'quasisteady-state' procedures have been used previously to determine the shift of the temperature of maximum density of water solutions [10]. In a typical controlled cooling experiment, $T_{\mathrm{h}}$ is initially held at $10^{\circ} \mathrm{C}$ and $T_{\mathrm{c}}$ at $6{ }^{\circ} \mathrm{C}$ until the average temperature of the test sample reaches $8{ }^{\circ} \mathrm{C}$ (as measured by a series of thermistors deployed horizontally across the sample along the central axis - see Fig. 1). $T_{\mathrm{h}}$ and $T_{\mathrm{c}}$ are then decremented by $0.1^{\circ} \mathrm{C}$ at 9 -min intervals until $T_{\mathrm{h}}$ reaches $2{ }^{\circ} \mathrm{C}$ and $T_{\mathrm{c}}$ reaches $-2{ }^{\circ} \mathrm{C}$. The entire experiment lasts for 81 steps (approximately $12 \mathrm{~h}$ ) during which time the sample is gradually cooled from $8{ }^{\circ} \mathrm{C}$ to $0{ }^{\circ} \mathrm{C}$. This procedure reveals details of changes which occur in the test sample as it is taken through the vicinity of the density maximum at $3.98^{\circ} \mathrm{C}$; the profiles of the thermistors embedded in the sample yield information on the changes in the convective flow, while thermistors on either side of the sample give information on changes in the rate of heat flowing through the test region, based on a modification to the longitudinal comparative cut-bar method (Section 2.1).

\subsection{Steady-state experiments}

In this procedure, the temperatures on the left wall $\left(T_{\mathrm{L}}\right)$ and right wall $\left(T_{\mathrm{R}}\right)$ of the test chamber are held fixed for long time spans, and the rate of heat transfer is extracted after steady-state conditions have been established. To measure asymmetry in the rate of heat transfer, the temperature gradient across the sample would then be reversed, and the system allowed to reach steady-state conditions again. Equivalently, the test chamber could be rotated through $180{ }^{\circ} \mathrm{C}$ about a vertical axis. Gradient reversal was more usual, however, as it could be easily achieved under computer control without the necessity of human intervention. The degree of asymmetry is quantified by the relative change in the rate of heat flow:

Heat flow rectification, $r=\frac{\left(H_{\mathrm{H}}-H_{\mathrm{L}}\right)}{H_{\mathrm{H}}}$

Thus, a rectification of $0 \%$ would indicate no asymmetry, whereas a value of ' $r$ ' of $100 \%$ would indicate perfect heat rectification (no heat flow for one orientation of the temperature gradient). In typical steady-state experiments, the values of $T_{\mathrm{L}}$ and $T_{\mathrm{R}}$ are chosen and the test region is then held under this gradient for a relatively long interval (a duration of $8 \mathrm{~h}$ is typically allowed for this). The gradient is then reversed over a period of $13 \mathrm{~h}$, and the system is once again allowed to settle to steady-state conditions. This cycle is repeated several times. With uncertainties of $5 \%$ on the heat transfer rates, an uncertainty of the order of $10 \%$ applies to experimentally determined values of the rectification factor.

\section{Experimental results}

Results are presented initially for heat transfer measurements through water in the vicinity of the density maximum. These are followed by results from experiments designed to measure heat transfer asymmetry. In all cases a moving average of $1500 \mathrm{~s}$ is applied to the data to smooth the effects of oscillations induced in the thermistor profiles arising from the servo control of $T_{\mathrm{h}}$ and $T_{\mathrm{c}}\left(T_{\mathrm{L}}\right.$ and $T_{\mathrm{R}}$ in the case of asymmetry measurements). These oscillations are negligible on the profiles associated with the thermistors located within the fluid in the test region, but are more pronounced on the profiles associated with $T_{\mathrm{m}, \mathrm{h}}$ and $T_{\mathrm{m}, \mathrm{c}}$ ( $T_{\mathrm{m}, \mathrm{L}}$ and $T_{\mathrm{m}, \mathrm{R}}$ in the case of asymmetry measurements).

\subsection{Controlled cooling experiments}

Figs. 2 and 3 show results from controlled cooling experiments on ethanol and water, respectively. In both 
experiments the test sample was subjected to a $4{ }^{\circ} \mathrm{C}$ temperature difference across $12 \mathrm{~cm}$ of fluid, with the mean temperature decreased in $0.1{ }^{\circ} \mathrm{C}$ steps from $8{ }^{\circ} \mathrm{C}$ to $0{ }^{\circ} \mathrm{C}$ as described in Section 2.1. For ethanol, the five thermistors within the fluid show similar profiles: the central region of the fluid remains relatively undisturbed by the clockwise recirculation convective cell which flows predominantly around the perimeter of the enclosure and thus all of the thermistors show the slow cooling from $8{ }^{\circ} \mathrm{C}$ to $0{ }^{\circ} \mathrm{C}$ in a linear manner. The $T_{\mathrm{h}}$ and $T_{\mathrm{c}}$ profiles show the stepped decrease in temperature of the side chambers over the 12-h time span. The $T_{\mathrm{m}, \mathrm{h}}$ profile remains consistently at $0.9^{\circ} \mathrm{C}$ above the $T_{\mathrm{h}}$ profile, indicating a constant heat transfer rate through the hot-side reference material of $0.49 \mathrm{~W}$. The $T_{\mathrm{m}, \mathrm{c}}$ profile remains consistently at $1.3{ }^{\circ} \mathrm{C}$ below the $T_{\mathrm{c}}$ profile, indicating a heat transfer rate of $0.7 \mathrm{~W}$ through the cold-side Perspex reference material. This heat transfer rate is higher than that through the hot-side reference material, as expected (Section 2.1). The additional $0.21 \mathrm{~W}$ arises from the gradual cooling of the ethanol sample. A CFD model of this experiment confirms these heat transfer rates (Section 4.1).

The corresponding plot for water exhibits different behaviour in the region centred around $4{ }^{\circ} \mathrm{C}$ (Fig. 3). The dispersion of the five embedded thermistor profiles arises due to the formation and development of a second, counterclockwise convective cell, which begins at the cold wall of the test chamber and gradually grows from right to left until it becomes the dominant single convective cell for temperatures below the temperature of density maximum (see [10] for further details). The $T_{\mathrm{h}}$ and $T_{\mathrm{c}}$ profiles are as in Fig. 2, but the $T_{\mathrm{m}, \mathrm{h}}$ profile dips towards the end of the region spanned by the dispersed test region profiles, whereas the $T_{\mathrm{m}, \mathrm{c}}$ profile rises near the start of this region. This is to be expected, as the second convective cell starts to develop at the cold wall and its influence on the rate of heat transfer will be first detected by the monitoring thermistor at the cold-side Perspex reference material. It takes about seven time steps for the second convective cell to grow across the entire test region, by which time its influence is being reflected in the dip of the $T_{\mathrm{m}, \mathrm{h}}$ profile. Both the rise in $T_{\mathrm{m}, \mathrm{c}}$ and the dip in $T_{\mathrm{m}, \mathrm{h}}$ indicate a decrease in the rate of heat flowing through the respective reference materials; the heat transfer rate through the reference material on the hot side of the sample decreases from $0.83 \mathrm{~W}$ to $0.16 \mathrm{~W}(80 \%$ reduction) when the water is brought through the anomaly region. The detailed profiles and values of heat transfer are in good agreement with predictions from CFD (Section 4).

The reduction in the rate of heat transfer in the vicinity of the density maximum arises from two contributions: the formation of a double convective cell reduces direct thermal communication between the hot and cold walls [1], and the flattening of the density state function (density as a function of temperature) of water near the density extremum results in an overall reduction in buoyancy as the convective velocity is reduced.

\subsection{Steady-state experiments}

The reduction in the thermal conductance of a region of water subject to a horizontal temperature gradient which encompasses the temperature of the density maximum will give rise to an asymmetry in heat transfer across a composite system consisting of water and some other substance. Fig. 4a shows a schematic of a double chamber structure which has been the main focus of the experimental and computational studies reported here. The system consists of a chamber constructed from $6 \mathrm{~mm}$ Perspex with $6 \mathrm{~mm}$ Aluminium side walls and a $1 \mathrm{~mm}$ Aluminium central partition. Each sub-chamber has a volume of $6 \times 6 \times 6 \mathrm{~cm}^{3}$. The chamber on the right is filled with pure water with a temperature of maximum density of $3.98{ }^{\circ} \mathrm{C}$, and the chamber on the left contains a saline solution with a temperature of maximum density of $2.0^{\circ} \mathrm{C}(9.0 \mathrm{~g} / \mathrm{l}$ of $\mathrm{NaCl}$ solution; the temperature of maximum density was measured using a technique described previously [10]). For convenience this system will be referred to as the water-saline diode (a composite system of pure water and a saline solution). In the low-conductance mode, the pure water is adjacent to $T_{\mathrm{h}}$ and the saline solution is adjacent to $T_{\mathrm{c}}$; a gradient imposed
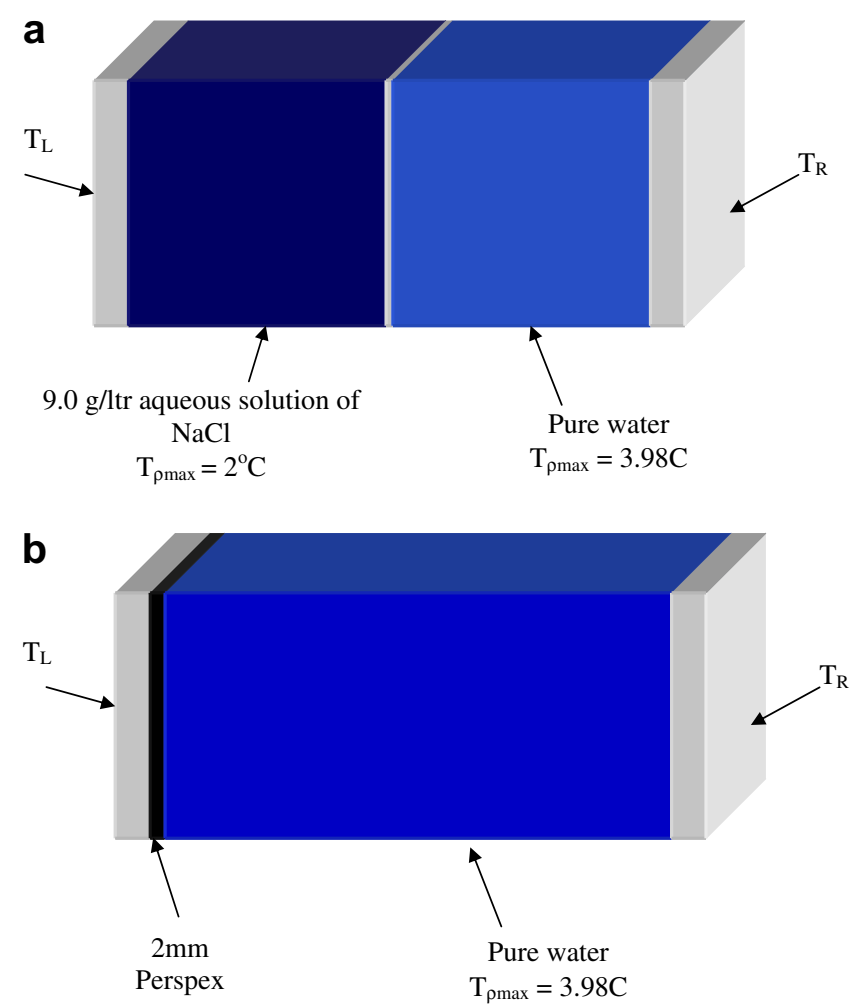

Fig. 4. (a) Schematic diagram of the test chamber used to study the water/ water-solution thermal diode effect. The device consists of two compartments separated by an aluminium partition. One compartment contains pure water with a temperature of maximum density of $3.98^{\circ} \mathrm{C}$, while the other compartment contains a saline solution $(9.0 \mathrm{~g} / 1$ of $\mathrm{NaCl})$ with a temperature of maximum density of $2.0^{\circ} \mathrm{C}$. The end walls are made from $6 \mathrm{~mm}$ aluminium. (b) Test chamber used to study the water-perspex thermal diode effect. A $0.2 \mathrm{~cm}$ layer of Perspex is placed in contact with $11.8 \mathrm{~cm}$ of water; both are held between $6 \mathrm{~mm}$ aluminium end walls. 
by $T_{\mathrm{h}}$ of $5^{\circ} \mathrm{C}$ and $T_{\mathrm{c}}$ of $1^{\circ} \mathrm{C}$ gives rise to conditions of maximum density in both chambers, with a resulting heat transfer rate of $0.19 \mathrm{~W}$. With the gradient reversed, or the order of the chambers inverted, neither chamber has temperature conditions suitable for the formation of double convective cells, and the rate of heat transfer increases to $0.55 \mathrm{~W}$. The resulting rectification for this configuration is thus $65.4 \%$. Fig. 5 shows results from a 4-day experiment using this system, with the gradient being reversed under computer control at intervals of $21 \mathrm{~h}(8 \mathrm{~h}$ in steady state followed by $13 \mathrm{~h}$ during which the gradient is reversed). It is evident from the $T_{\mathrm{m}, \mathrm{L}}$ and $T_{\mathrm{m}, \mathrm{R}}$ profiles that the heat transfer rate is lower in regions a, c, and e compared to regions $b$ and $d$. It is also apparent from the profiles of the thermistors embedded in both chambers (two thermistors per chamber in this case) that the convective flow is different for these alternate regions of the graph. A spreading out of the profiles in regions $\mathrm{a}, \mathrm{c}$, and $\mathrm{e}$ indicates the formation of double convective cells, whereas clustering of the thermistor profiles in regions b, $d$ indicates the presence of single convective cells. These results are confirmed by CFD models (Section 4.2). The undulations in the horizontal regions of the $T_{\mathrm{L}}$ and $T_{\mathrm{R}}$ profiles (and the monitor profiles) are due to the feedback required within the system to maintain a constant temperature difference across the test region during steady-state conditions. Similar undulations are also evident in Figs. 2 and 3, but in those cases the variations are partly due to the regular stepping of the side-chamber temperatures during the controlled cooling. It should be noted that the results are insensitive to the size of the time steps in such experiments provided the

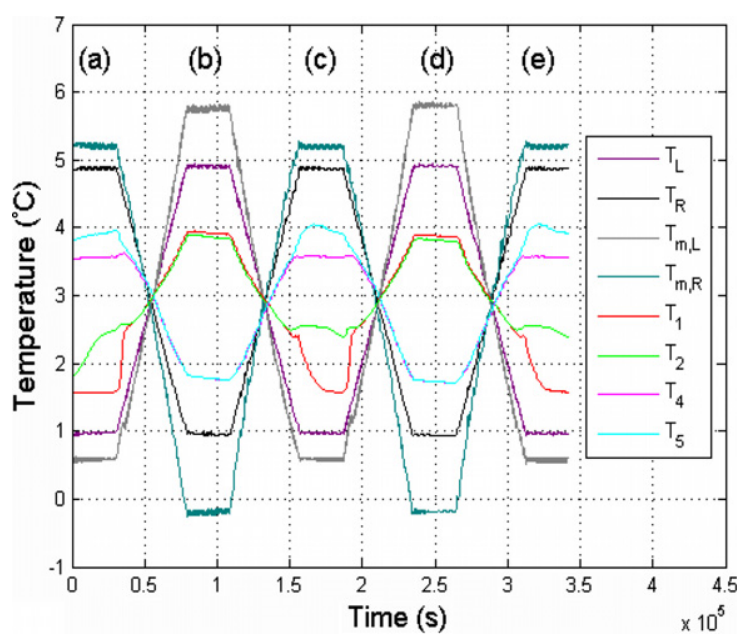

Fig. 5. Experimental results for a long-duration test with the water-saline diode. Regions a, $\mathrm{c}$ and $\mathrm{e}$ are in the low-conductance mode; regions $\mathrm{b}$ and $\mathrm{d}$ are in the high-conductance mode. The temperature gradient was reversed under computer control in the cross-over intervals between the five regions labelled a-e. Thermistors $T_{1}$ and $T_{2}$ are located in the compartment containing the saline solution (left compartment), and thermistors $T_{4}$ and $T_{5}$ are located in the compartment containing the pure water (right compartment). The central thermistor $\left(T_{3}\right)$ was removed to permit insertion of the aluminium partition. The experimental heat transfer rates are also indicated in Fig. 9b, where they are compared against CFD results. overall cooling rate is sufficiently slow that the cooling of the test region can keep pace with the cooling of the side chambers.

Another system which exhibits thermal rectification properties consists of a region of water adjacent to a solid. Fig. 4b shows one possible arrangement: a $12 \mathrm{~cm}$ wide region consists of $11.8 \mathrm{~cm}$ of water (on the right) and $0.2 \mathrm{~cm}$ of Perspex (on the left), with the composite system constituting the test region which is held between $T_{\mathrm{L}}$ and $T_{\mathrm{R}}$. With $T_{\mathrm{L}}$ and $T_{\mathrm{R}}$ held at $6.5^{\circ} \mathrm{C}$ and $2.5^{\circ} \mathrm{C}$ respectively (i.e. Perspex adjacent to the hot wall, and water adjacent to the cold wall), the water is held at temperatures in the vicinity of the density maximum, and its conductance is lowered. With either the gradient reversed or with the order of the materials inverted (Perspex adjacent to the cold wall, water adjacent to the hot wall) the water no longer encompasses the temperature of the density maximum, and its conductance increases. The conductance of the Perspex is approximately the same in both cases (being relatively insensitive to changes in absolute temperature over a wide range of values). Experiments with such an arrangement yield heat transfer rates of $0.51 \mathrm{~W}$ and $0.33 \mathrm{~W}$ for the two modes, giving a heat transfer rectification factor of $35 \%$. A CFD model for this configuration predicts somewhat higher heat transfer rates of $0.55 \mathrm{~W}$ and $0.34 \mathrm{~W}$ for the two modes with a resulting rectification factor of $38 \%$ (Section 4.2).

\section{CFD studies}

Computational fluid dynamics (CFD) have been used to augment the experimental studies and to investigate the variation in heat transfer rectification as functions of temperature, gradient, and structure of the composite systems. The modelling has been carried out using the Comsol Multiphysics environment [14] in 2-dimensional mode. Material properties such as viscosity, heat capacity, and thermal conductivity were varied as a function of temperature using data taken from [15]. A nonlinear density state function was used for water to model the effects of the density extremum; a second-order polynomial fit to data from [15] was used in this work, as higher order polynomial fits were found to be of negligible difference over the temperature range of interest. The density was varied as a function of temperature in all relevant terms of the Navier-Stokes equations. The following system of coupled equations were used:

$$
\begin{aligned}
& \nabla \cdot \mathbf{v}=0 \\
& \rho(T) \frac{\partial \mathbf{v}}{\partial t}+\rho(T)(\mathbf{v} \cdot \nabla) \mathbf{v}=-\nabla p+\rho(T) \mathbf{g}+\mu(T) \nabla^{2} \mathbf{v} \\
& \frac{\partial T}{\partial t}+\mathbf{v} \cdot \nabla T=\frac{k(T)}{\rho(T) C_{p}(T)} \nabla^{2} T \\
& \begin{aligned}
\rho(T) & =c_{0}+c_{1} T+c_{2} T^{2} \\
\rho(T) & =c_{0}+c_{1}\left(T-\left(T_{\rho \max }-T_{\rho \max , \mathrm{sol}}\right)\right) \\
& \quad+c_{2}\left(T-\left(T_{\rho \max }-T_{\rho \max , \mathrm{sol}}\right)\right)^{2}
\end{aligned}
\end{aligned}
$$


where $\mathbf{v}$ is velocity, $\rho(T)$ is the density as a function of temperature, $p$ is pressure, $\mathbf{g}$ is the local acceleration due to gravity, $\mu(T)$ is the dynamic viscosity, $k(T)$ is the thermal conductivity, and $\mathrm{C}_{p}(T)$ is the specific heat capacity (at constant pressure). The coefficients in Eqs. (7) and (8) have the values: $c_{0}=999.845079 \mathrm{~kg} \mathrm{~m}^{-3}, \quad c_{1}=0.06378$ $\mathrm{kg} \mathrm{m}^{-3}{ }^{\circ} \mathrm{C}^{-1}, \quad c_{2}=-0.0080125 \mathrm{~kg} \mathrm{~m}^{-3}{ }^{\circ} \mathrm{C}^{-2}, \quad T_{\rho \max }=$ $3.98^{\circ} \mathrm{C}$ and $T_{\rho \text { max sol }}=2.0^{\circ} \mathrm{C}$.

Fig. 6 a shows the boundary conditions for a representative sample of the 2-D CFD models relevant to this work, namely the water-saline diode. The vertical side walls are isothermal at temperatures $T_{\mathrm{L}}$ and $T_{\mathrm{R}}$. The top and bottom walls of the region are adiabatic. Subdomain 1 contains fluid with properties of the saline solution (temperature of maximum density of $2.0^{\circ} \mathrm{C}$ ), subdomain 2 is solid with $k=200 \mathrm{~W} \mathrm{~m}^{-1} \mathrm{~K}^{-1}$ (the aluminium partition) and subdomain 3 contains fluid with properties of pure water with a temperature of maximum density of $3.98^{\circ} \mathrm{C}$. No-slip conditions apply to all walls in contact with the fluids. Dimensions are as indicated in Fig. 6a and match the dimensions of the chambers used in the experiments. Fig. $6 \mathrm{~b}$ shows the density state functions for pure water and a water solution with a temperature of maximum density at $2.0^{\circ} \mathrm{C}$. It is evident from this figure that the density ranges (and hence the effects of buoyancy) of the two fluids within the tempera-
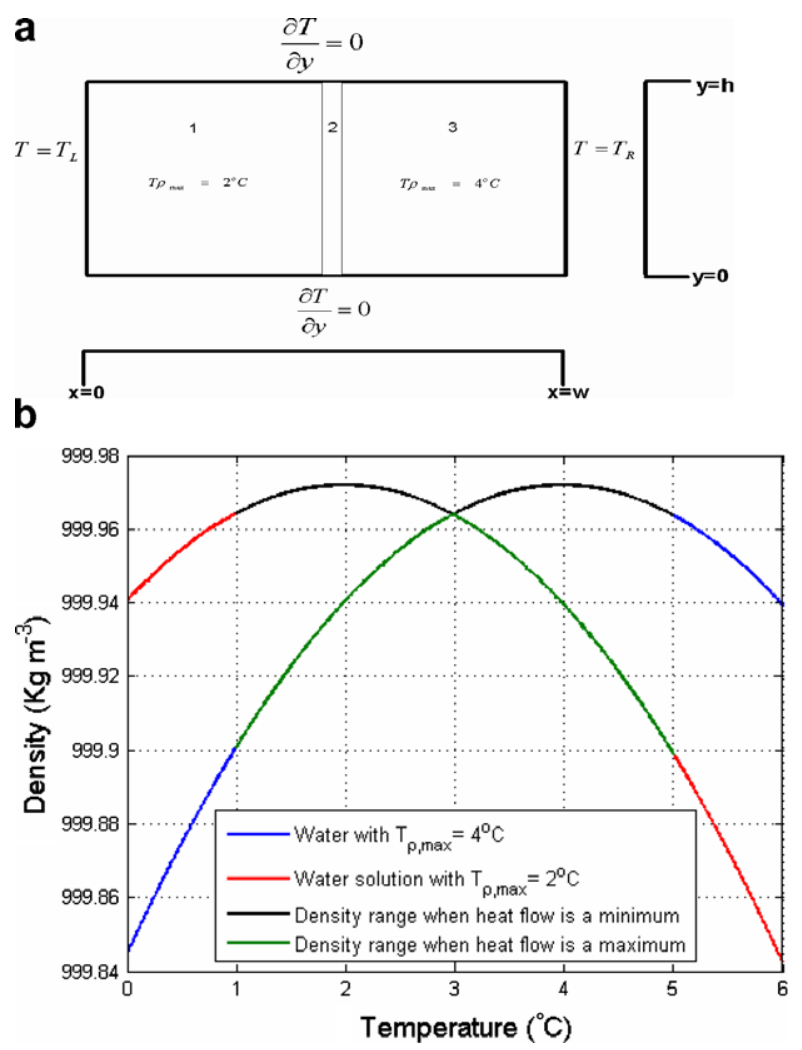

Fig. 6. (a) Boundary conditions used in the CFD model of the watersaline diode. Domain 1 contains fluid with a density maximum at $2{ }^{\circ} \mathrm{C}$, domain 2 consists of an aluminium partition, and domain 3 contains fluid with a density maximum at $4{ }^{\circ} \mathrm{C}$. (b) Density state functions for pure water and a water solution with a temperature of maximum density of $2.0^{\circ} \mathrm{C}$. ture range $1-5^{\circ} \mathrm{C}$ are different depending on the orientation of the temperature gradient. For the lowconductance mode, the relatively narrow regions of the density functions between $999.964 \mathrm{~kg} \mathrm{~m}^{-3}$ and the peaks at $999.972 \mathrm{~kg} \mathrm{~m}^{-3}$ will be activated (a density range of less than $0.01 \mathrm{~kg} \mathrm{~m}^{-3}$ ), while in the high-conductance mode the broader regions of the two curves between $999.90 \mathrm{~kg} \mathrm{~m}^{-3}$ and $999.964 \mathrm{~kg} \mathrm{~m}^{-3}$ will be activated (a density range of $0.064 \mathrm{~kg} \mathrm{~m}^{-3}$ ). It is further evident from the pure water density profile in Fig. $6 \mathrm{~b}$ that the density range changes for a fixed temperature span as the region of the density maximum is approached (e.g. moving from the region encompassed by $1{ }^{\circ} \mathrm{C}$ and $2{ }^{\circ} \mathrm{C}$, to $2^{\circ} \mathrm{C}$ and $3{ }^{\circ} \mathrm{C}$ ). Thus a reduction in buoyancy - and hence convective heat transfer - will arise even when the temperature of the density maximum is not encompassed in the temperature gradient.

Additional CFD studies were carried out to check for the possible influence on the experimental results of variations of temperature along the vertical containing walls of the test chamber (assumed to be isothermal in the models used for Sections 4.1, 4.2 and 4.3). This was done by modelling the influence of Aluminium walls $(k=200$ $\mathrm{W} \mathrm{m}{ }^{-1} \mathrm{~K}^{-1}$ ) with a thickness of $6 \mathrm{~mm}$. It was found that the temperature variations along such walls in contact with the fluid were of the order of $0.02 \mathrm{~K}$, which is below the resolution of the experimental thermometry. The reasonable agreement between experimental and CFD results (from the isothermal wall models) further indicates that such variations do not have a significant influence on the results.

The sensitivity of the numerical solution to the grid density was analysed using uniform grids in the range $20 \times 10$ (width by height) to $60 \times 30$. The behaviour of a global parameter (the integral of the temperature over the entire grid for the controlled cooling model) was examined for convergence, and it was found that the value of the average temperature was independent of the grid size for grids in excess of $50 \times 20$ (less than $1 \%$ variation in the average temperature above this mesh size, compared with a $13 \%$ variation in this parameter in going from a $10 \times 20$ to a $15 \times 30$ grid). Similar tests were carried out for the steady-state model, using the heat transfer rate as the global parameter.

\subsection{CFD - controlled cooling}

For this CFD model a single 2-D region of ethanol or water was assumed, of dimensions $0.12 \mathrm{~m}$ (width) by $0.06 \mathrm{~m}$ (height). The isothermal walls at $T_{\mathrm{h}}$ and $T_{\mathrm{c}}$ were decremented by $0.1{ }^{\circ} \mathrm{C}$ at 9 -min intervals to match experimental conditions (Section 3.1). Fig. 7 shows the results from this model with ethanol as the working fluid, which may be compared with Fig. 2 from the experimental work. Fig. 8 shows the corresponding simulation for pure water, which may be compared with the experimental results shown in Fig. 3. The heat transfer is obtained from the Comsol Multiphysics model by performing a boundary integration of the normal total heat flux. Direct compari- 


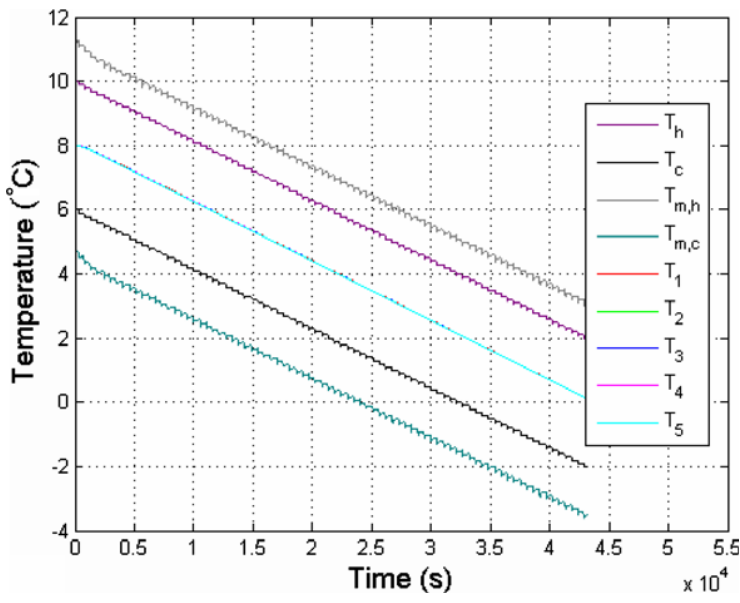

Fig. 7. CFD simulation of the controlled cooling experiment on ethanol.

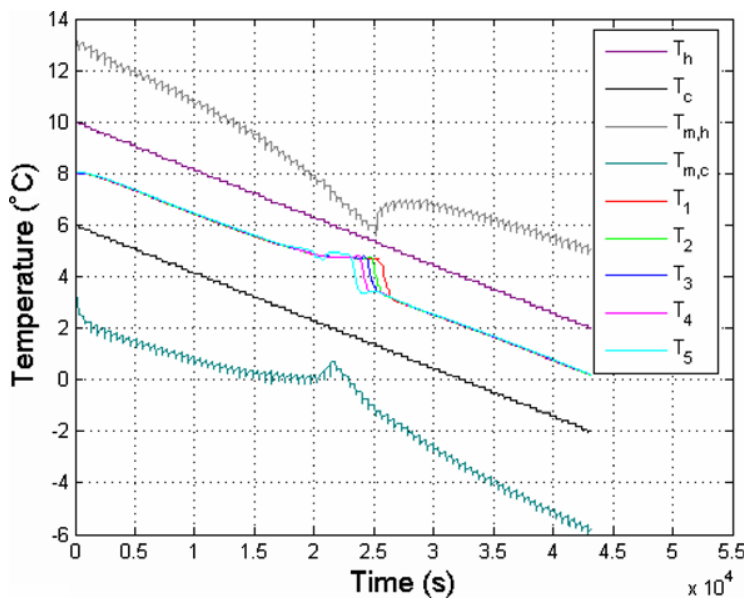

Fig. 8. CFD simulation of the controlled cooling experiment on water.

son between the 2-D model results and the 3-D experimental measurements may be made by multiplying the CFD heat transfer results (in $\mathrm{W} \mathrm{m}^{-1}$ ) by the depth of the 3-D chamber ( $0.06 \mathrm{~m}$ in the $z$-direction). To facilitate comparison with the experimental results, the heat flows into and out of the 2-D region are converted into temperatures which would be sensed if $1.25 \mathrm{~mm}$ Perspex reference materials were in place on either side of the test region, as is done in the experimental arrangement. These heat flux monitoring temperatures are displayed as curves above and below the $T_{\mathrm{h}}$ and $T_{\mathrm{c}}$ curves in Figs. 7-9. It is evident that there is reasonable agreement between the predictions of the CFD model and the observations from the experimental system. In particular, the magnitude and variation of the measured heat transfer rates are in good agreement, despite the fact that the experimental results rely on temperature measurements made using single thermistors on either side of the Perspex reference materials, compared to a boundary integration in the case of the CFD model. The difference between the rates of heat transfer into and out of the fluid region is also apparent from the CFD model, and is due to the separate contributions made by
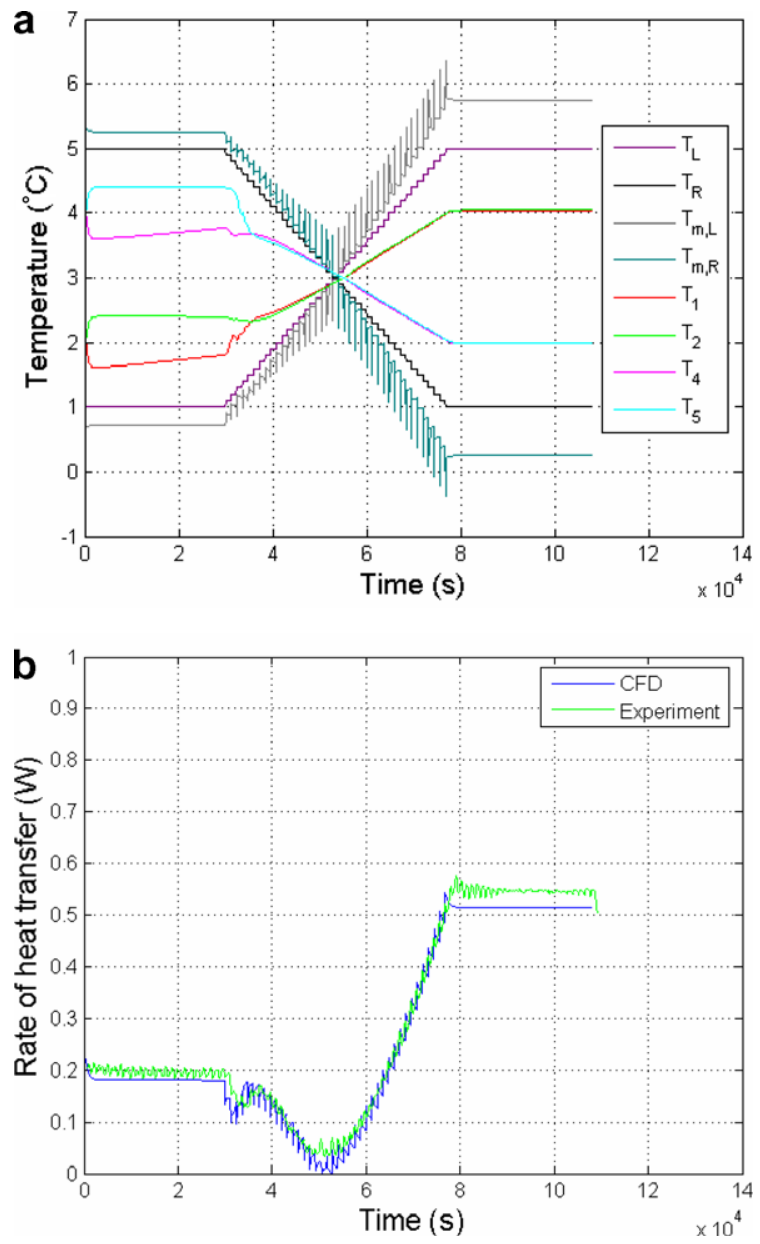

Fig. 9. CFD simulation of the performance of the water-saline diode. (a) Low-conductance mode followed by high-conductance mode, with changes in rate of heat transfer indicated by changes in $T_{\mathrm{m}, \mathrm{L}}$ and $T_{\mathrm{m}, \mathrm{R}}$, as in Fig. 5. (b) Heat transfer rates for low- and high-conductance modes, with experimental rates indicated for comparison (from Fig. 5).

the presence of the temperature gradient and by the slow cooling of the sample, as discussed in Section 3.1.

\subsection{CFD - steady-state model}

In this model, the temperature-decrementing model of Section 4.1 was modified so that $T_{1}$ and $T_{\mathrm{r}}$ were held at fixed values (of $5{ }^{\circ} \mathrm{C}$ and $1{ }^{\circ} \mathrm{C}$, or vice versa) for 8 -h intervals between gradient reversals, which took place over intervals of $13 \mathrm{~h}$ to match experimental conditions. The initial temperature of the pure water was set to $4{ }^{\circ} \mathrm{C}$, and that of the saline solution at $2{ }^{\circ} \mathrm{C}$. Results from the CFD model for the water-saline diode are shown in Fig. 9 and may be compared with the experimental results of Fig. 5. The values of heat transfer rates, after adjustment to allow for the depth of the 3-D experiment, are in good agreement with those observed experimentally, as are the overall trends followed by the thermistor profiles in the experiment and the temperatures at the corresponding probe positions in the CFD model. The model predicts a heat transfer rate of 

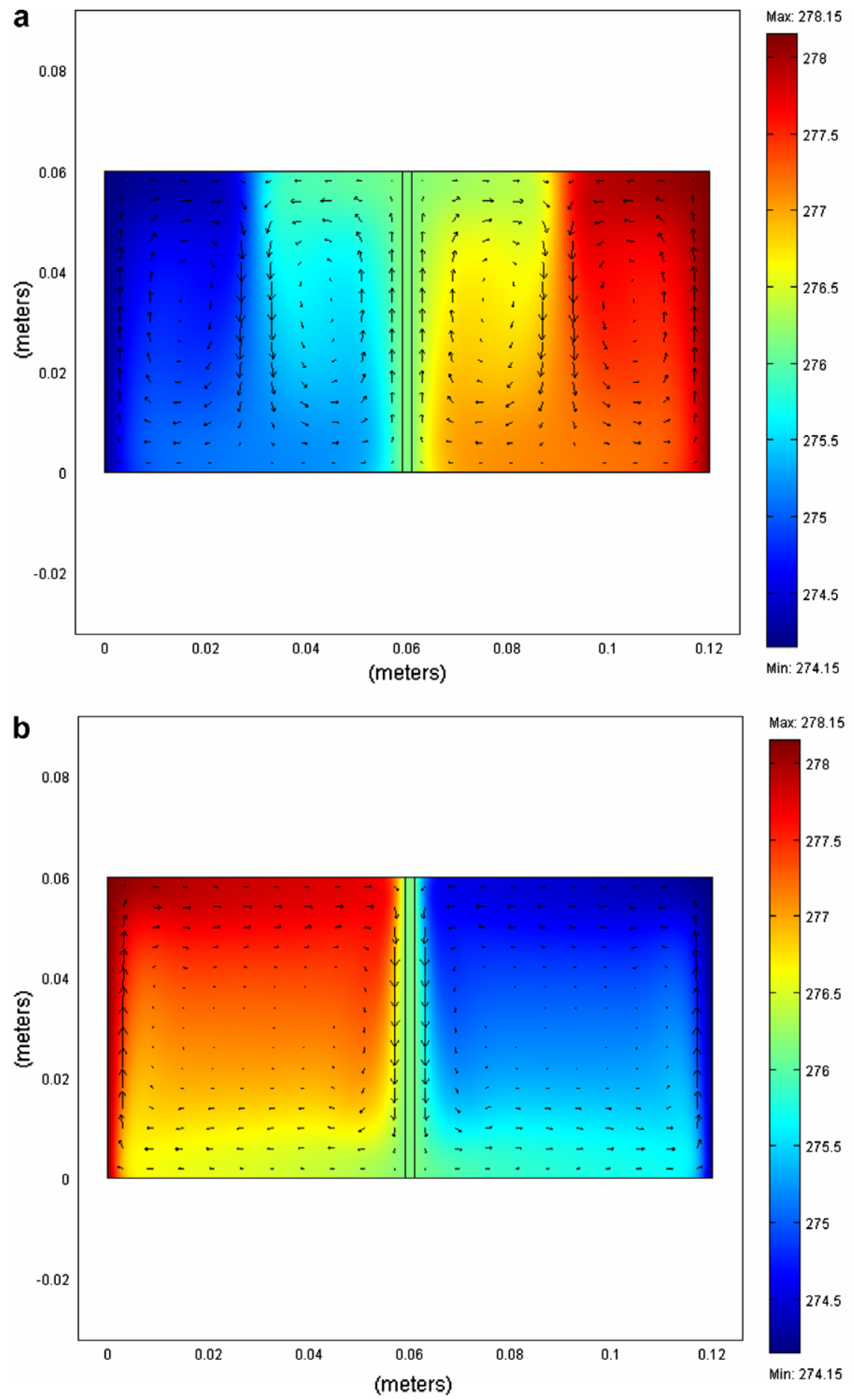

Fig. 10. CFD results for the flow patterns (quiver plots) and temperature fields (surface plots; degrees Kelvin) in the two conductance modes of the watersaline diode (saline solution on the left, pure water on the right). (A) Low-conductance mode: $T_{\mathrm{L}}$ set to $T_{\mathrm{c}}, T_{\mathrm{R}}$ set to $T_{\mathrm{h}}$. (B) High-conductance mode: $T_{\mathrm{L}}$ set to $T_{\mathrm{h}}, T_{\mathrm{R}}$ set to $T_{\mathrm{c}}$.

$0.18 \mathrm{~W}$ for the low-conductance mode, and $0.52 \mathrm{~W}$ for the high-conductance mode, yielding a rectification factor of $65.4 \%$. The convective flow patterns and the temperature fields are shown for both conductive modes of the watersaline diode in Fig. 10. The low-conductance mode in Fig. 10a shows the presence of double convective cells in both sides of the cavity, whereas single convective cells appear in each half of the device for the high-conductance mode shown in Fig. 10b. The temperature surface plots indicate that the gradient is reversed between Fig. 10a and $\mathrm{b}$ (cold on the left in Fig. 10a; cold on the right in Fig. 10b). A typical value for the Rayleigh number is estimated to be $6 \times 10^{5}$ for each side of the cavity (high-conductance mode, Fig. 10b). 
For the water-perspex composite system, the CFD model predicts a $38 \%$ rectification, which is in reasonable agreement with that found experimentally. The absolute values of the rates of heat transfer in both low and highconductance modes are $0.34 \mathrm{~W}$ and $0.55 \mathrm{~W}$ from the CFD model, which are somewhat higher than the heat transfer rates found experimentally, but the asymmetrical heat transfer associated with both the water-solid composite and the water-saline diode are confirmed by the CFD models.

\subsection{CFD - optimization studies}

CFD models have been used to investigate the degree of heat flow asymmetry as functions of (i) temperature (with fixed gradient magnitude), (ii) gradient magnitude (with fixed central temperature), (iii) aspect ratio (variable cavity length for fixed height), and (iv) number of compartments in the rectifier. Results of such studies are summarized in Figs. 11-14 for the water-saline diode and in Figs. 15 and 16 for the water-solid composite system.

\subsubsection{Water-saline diode optimization}

Results of optimization studies where the magnitude of the temperature gradient is held fixed at $4{ }^{\circ} \mathrm{C}$ are shown in Fig. 11. The mean temperature (average of the boundary temperatures) is varied from $0{ }^{\circ} \mathrm{C}$ to $6{ }^{\circ} \mathrm{C}$. As expected, the optimal rectification occurs when both chambers of the diode exhibit symmetrical double convective cells in the low thermal conductance configuration and single convective cells in the high-conductance configuration. This condition occurs for boundary temperatures of $5{ }^{\circ} \mathrm{C}$ and $1{ }^{\circ} \mathrm{C}$ with a mean temperature of $3{ }^{\circ} \mathrm{C}$, and gives rise to a rectification of $65.4 \%$. The secondary peaks at $1.39^{\circ} \mathrm{C}$ and $4.56^{\circ} \mathrm{C}$ correspond to situations where a double convective cell occurs in one chamber of the diode with a single convective cell in the other chamber (in the low thermal conductance configuration). Between the main peak and these secondary peaks the rectification goes to zero at mean temperatures of $1.78^{\circ} \mathrm{C}$ and $4.19^{\circ} \mathrm{C}$. Conditions at these temperatures are such that an increase in the thermal conductance of one compartment of the diode is counteracted by a decrease in the thermal conductance of the other compartment when the temperature gradient is reversed, leading to equal overall thermal conductivities for both directions of the gradient.

Rectification as a function of gradient magnitude for a fixed mean temperature (of $3{ }^{\circ} \mathrm{C}$ ) is shown in Fig. 12. The maximum rectification is achieved when the temperature difference is $4{ }^{\circ} \mathrm{C}$ and the boundary temperatures are $5{ }^{\circ} \mathrm{C}$ and $1{ }^{\circ} \mathrm{C}$. The symmetrical double convective cells which occur in each chamber of the diode under these boundary conditions become distorted for both larger and smaller temperature differences, leading to a reduction in the rectification factor.

The influence of the cavity aspect ratio on the rectification was investigated by holding the height fixed at $6 \mathrm{~cm}$

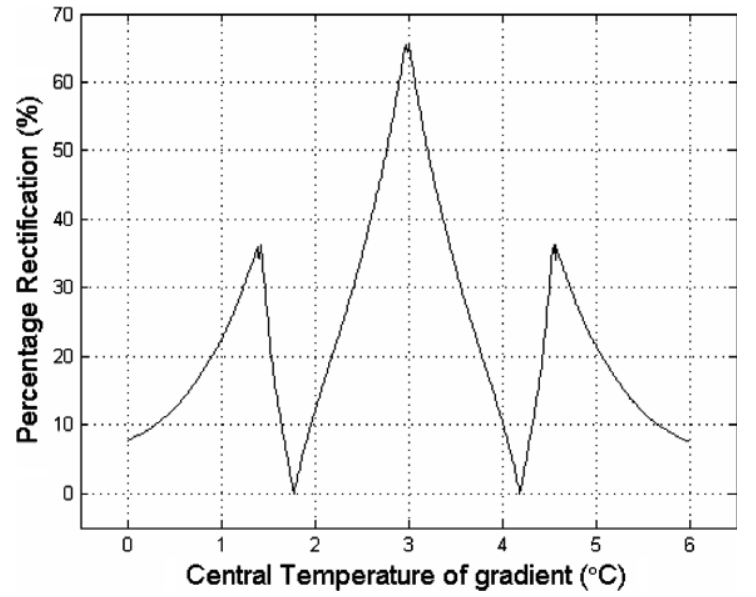

Fig. 11. CFD optimization study of the water-saline diode: the gradient is held fixed $\left(4{ }^{\circ} \mathrm{C}\right.$ across $\left.0.12 \mathrm{~m}\right)$ and the central temperature is varied from $0{ }^{\circ} \mathrm{C}$ to $6{ }^{\circ} \mathrm{C}$

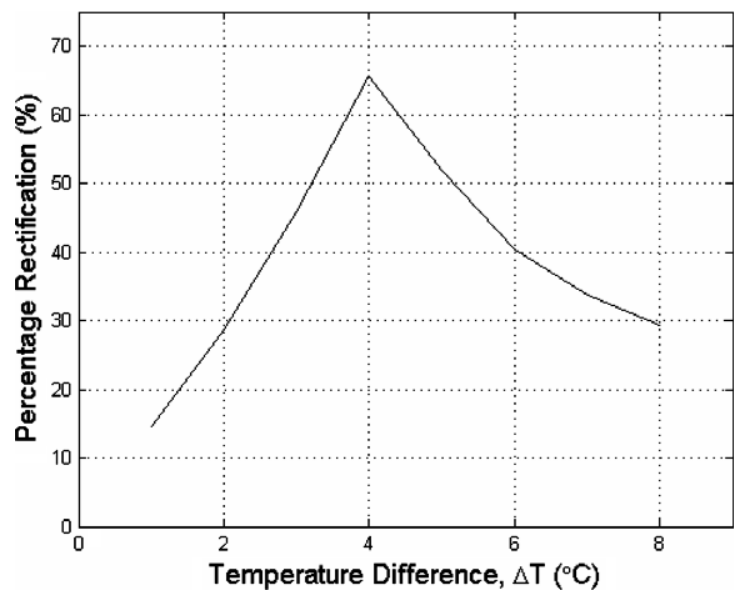

Fig. 12. CFD optimization study of the water-saline diode: the mean temperature of $T_{\mathrm{h}}$ and $T_{\mathrm{c}}$ is held fixed at $3{ }^{\circ} \mathrm{C}$, and the gradient is varied (from $1{ }^{\circ} \mathrm{C}$ to $8{ }^{\circ} \mathrm{C}$ across $0.12 \mathrm{~m}$ ).

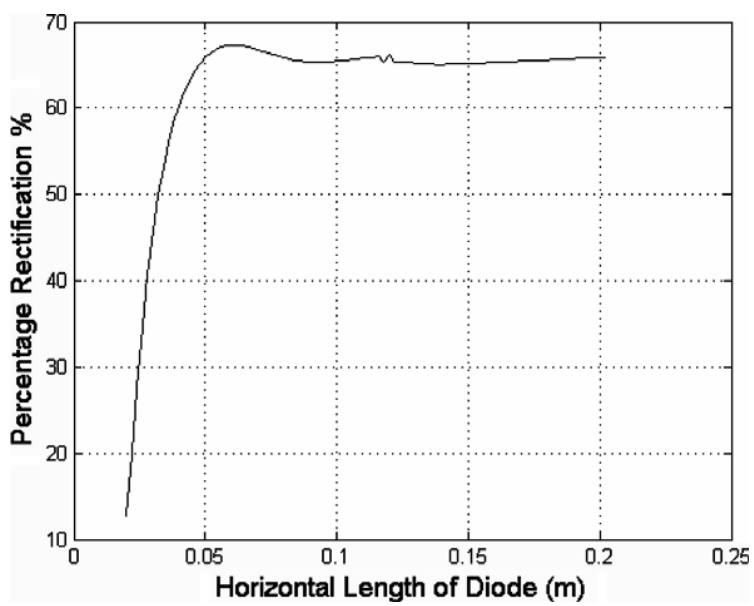

Fig. 13. CFD optimization study of the water-saline diode: percentage rectification as a function of horizontal length of the test chamber (varied from $2 \mathrm{~cm}$ to $22 \mathrm{~cm}$; height held fixed at $6 \mathrm{~cm}$ ). 


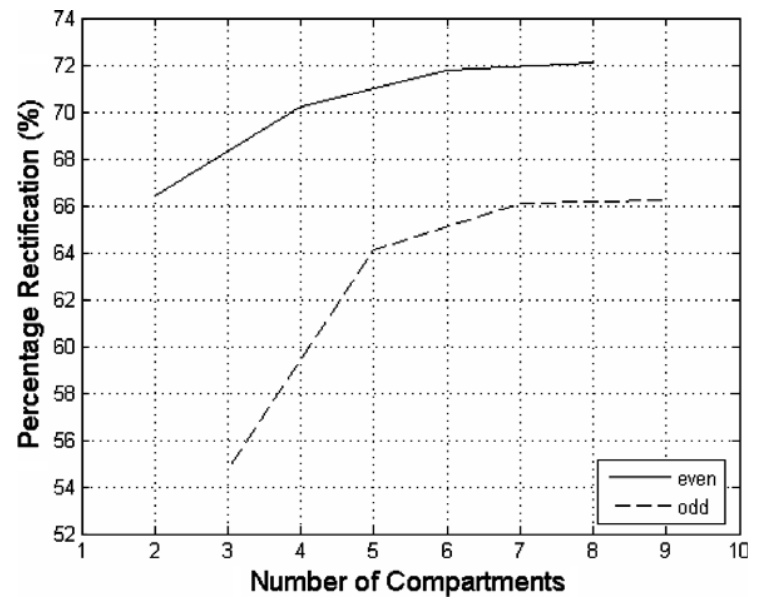

Fig. 14. CFD optimization study of the water-saline diode: percentage rectification as a function of number of compartments in the test region.

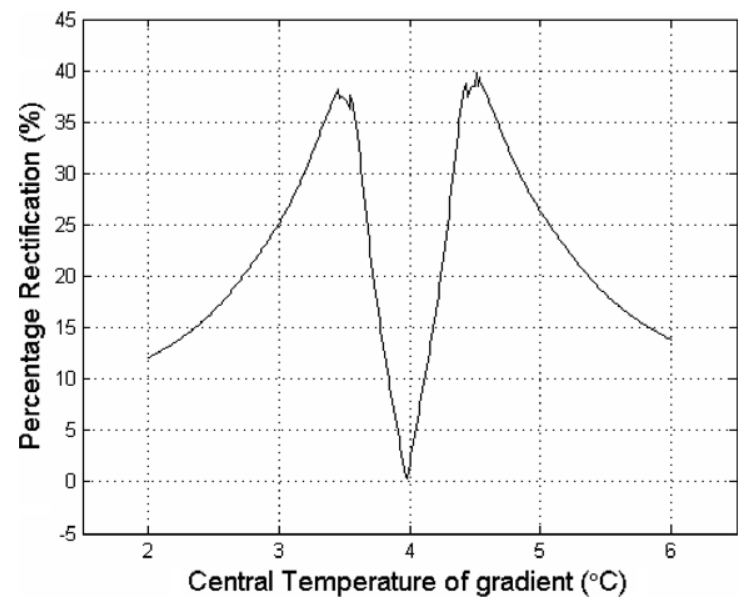

Fig. 15. CFD optimization study of the water-perspex diode: the gradient is held fixed $\left(4^{\circ} \mathrm{C}\right.$ across $\left.0.12 \mathrm{~m}\right)$ and the central temperature is varied from $2{ }^{\circ} \mathrm{C}$ to $6^{\circ} \mathrm{C}$.

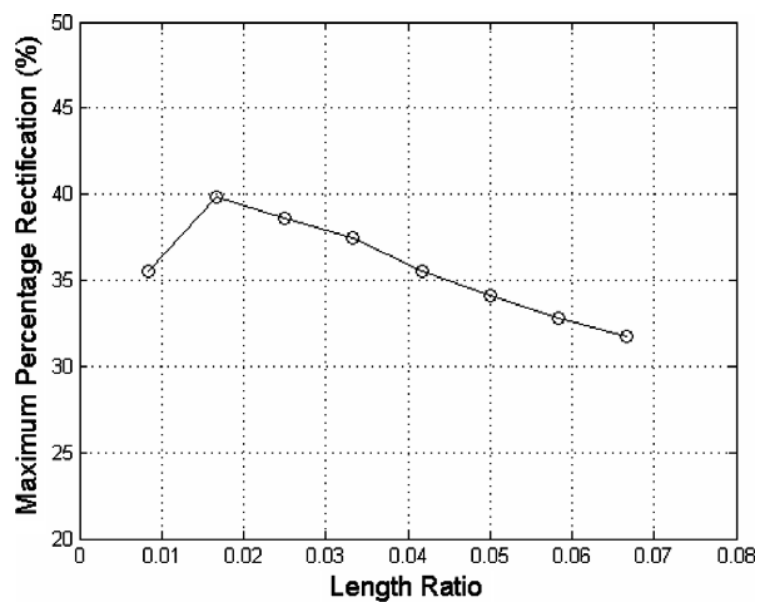

Fig. 16. CFD optimization study of the water-perspex diode: percentage rectification as a function of the ratio of the width of the Perspex to the width of the water (with the total length fixed at $12 \mathrm{~cm}$ ). The Perspex width is varied from $0.1 \mathrm{~cm}$ to $0.8 \mathrm{~cm}$. and varying the overall length of the diode from $2 \mathrm{~cm}$ to $22 \mathrm{~cm}$ (Fig. 13). A maximum rectification of $67 \%$ occurs for a cavity length of $6 \mathrm{~cm}$ (i.e. each chamber is $3 \mathrm{~cm}$ in length); this drops to $65 \%$ for larger cavity lengths, including the $12 \mathrm{~cm}$ length used in the experimental investigations. The influence of the absolute scale for a fixed aspect ratio (height to width of 1-2) was also investigated, yielding results similar to Fig. 13. A maximum rectification of $67 \%$ is reached at widths in excess of $6 \mathrm{~cm}$; the rectification declines rapidly for widths less than $3 \mathrm{~cm}$ due to the conduction component of the heat transfer which is present in both the low and high transfer modes (e.g. a water-saline diode of height $1 \mathrm{~cm}$ and width $2 \mathrm{~cm}$ has a rectification factor of $35 \%$ ).

The influence of the number of compartments in the cavity on the rectification is shown in Fig. 14. It is evident that the rectification behaves differently for odd and even numbers of compartments. The boundary temperatures were chosen for the even-numbered configurations such that double convective cells changed to single cells in each compartment upon reversing the temperature gradient. This arrangement is unobtainable for an odd number of compartments since the compartment in the centre will have a double convective cell for both orientations of the temperature gradient. Consequently, the rectification is greater for the even-numbered configurations, and rises to $72 \%$ for an arrangement of eight cells. It is evident, however, that only slight improvements will take place as the number of cells is increased.

\subsubsection{Optimization of the water-solid composite system}

The influence of the mean temperature on the percentage rectification for the composite system (with a fixed gradient magnitude of $4{ }^{\circ} \mathrm{C}$ ) is shown in Fig. 15. The system is assumed to consist of $11.8 \mathrm{~cm}$ of water and $0.2 \mathrm{~cm}$ of Perspex, with a height of $6 \mathrm{~cm}$. Maximum rectification occurs for mean temperatures of $3.5^{\circ} \mathrm{C}$ and $4.5^{\circ} \mathrm{C}$; in both cases there is a transition from a double to a single convective cell arrangement in the water when the gradient is reversed. The zero rectification at a mean temperature of $4{ }^{\circ} \mathrm{C}$ occurs due to the formation of similar convective patterns in the water for both orientations of the temperature gradient.

Rectification as a function of the ratio of length of water to length of Perspex is shown in Fig. 16. The total length of the composite system is maintained at $12 \mathrm{~cm}$, with the Perspex length ranging from $0.1 \mathrm{~cm}$ to $0.8 \mathrm{~cm}$. The maximum rectification of $40 \%$ occurs at a Perspex length of $0.2 \mathrm{~cm}$.

\section{Discussion and conclusions}

Heat rectification devices offer considerable possibilities in insulation, refrigeration, heat pumps, and control of heat flow in general. A variety of devices exist or have been proposed which offer varying degrees of thermal rectification (Table 1). A survey of these devices suggests that there are two independent conditions which can give rise to heat rectification; they shall be classified as Type I and Type II 
Table 1

Thermal rectifiers

\begin{tabular}{|c|c|c|c|}
\hline Device & Rectification $^{\mathrm{a}}$ & Reference & Notes \\
\hline \multicolumn{4}{|l|}{ Type I (body force) } \\
\hline Parallelogram enclosure & $75 \%{ }^{\mathrm{b}}$ & {$[19]$} & CFD \\
\hline Vertical fluid column & $88 \%{ }^{\mathrm{b}}$ & $\begin{array}{l}\text { This } \\
\text { work }\end{array}$ & CFD \\
\hline \multicolumn{4}{|l|}{ Type II (asymmetry) } \\
\hline Copper oxide rectifier & $53 \%$ & {$[3]$} & Experiment \\
\hline Metal junction & $50 \%$ & {$[5]$} & Theory $^{\mathrm{c}}$ \\
\hline Expansion rectifier & $65 \%$ & {$[4]$} & Experiment \\
\hline Nanotube rectifier & $7 \%$ & {$[20]$} & Experiment \\
\hline 1-D lattice & $48 \%$ & {$[6]$} & Theory \\
\hline 1-D lattice & $99 \%$ & {$[7]$} & Theory ${ }^{\mathrm{d}}$ \\
\hline Molecular junction & $34 \%$ & {$[8,9]$} & Theory \\
\hline Quartz-glass composite & $20 \%{ }^{\mathrm{b}}$ & $\begin{array}{l}\text { This } \\
\text { work }\end{array}$ & Simulation $^{\mathrm{e}}$ \\
\hline \multicolumn{4}{|c|}{ Hybrid (body force and asymmetry) } \\
\hline Water-saline diode & $65 \%$ & $\begin{array}{l}\text { This } \\
\text { work }\end{array}$ & $\begin{array}{l}\text { Experiment/ } \\
\text { CFD }\end{array}$ \\
\hline Water-perspex diode & $38 \%$ & $\begin{array}{l}\text { This } \\
\text { work }\end{array}$ & $\begin{array}{l}\text { Experiment/ } \\
\text { CFD }\end{array}$ \\
\hline PCM-solid composite & $50 \%{ }^{\mathrm{b}}$ & $\begin{array}{l}\text { This } \\
\text { work }\end{array}$ & CFD \\
\hline $\begin{array}{l}\text { Heat pump }+ \text { thermal } \\
\text { diode }\end{array}$ & Not stated & {$[18]$} & $\begin{array}{l}\text { Experiment/ } \\
\text { model }\end{array}$ \\
\hline
\end{tabular}

${ }^{\text {a }}$ Rectification factors are not stated in the publications in most cases. Some have been estimated for this work, but could vary over wide ranges depending on the assumed conditions. Most have yet to be verified experimentally.

${ }^{\mathrm{b}}$ Estimated for this work.

${ }^{\mathrm{c}}$ Metal junctions - some experimental evidence is cited, but it is not compelling (see [5]).

d In [7] the rectification was quantified by the ratio of high heat flow to low heat flow $\left(J_{+} / J_{-}\right)$. This is related to the rectification factor by $r=1-\left(J_{+} / J_{-}\right)^{-1}$

e Quartz-glass composite: Quartz, $k=-0.1 T+40$ (fit to data in [16]); Glass, $k=+0.003 T+0.4$ (fit to data in [17]), $T$ in degrees Kelvin. Composite of $20 \mathrm{~cm}$ quartz and $1 \mathrm{~cm}$ glass was assumed.

thermal rectifiers in the following discussion. Type I rectifiers require the presence of a body force, such as gravity or an external magnetic field (in the case of fluids with non-zero susceptibility), which gives rise to a preferred direction for heat flow. The simplest example of a Type I device is a column of fluid in a gravitational field with the temperature gradient applied vertically. With $T_{\mathrm{h}}$ below $T_{\mathrm{c}}$, convection will occur and the heat flow will be enhanced under normal buoyancy conditions. With $T_{\mathrm{h}}$ above $T_{\mathrm{c}}$, convection will be suppressed and the heat flow will be reduced. CFD simulations suggest that a relatively high rectification - of the order of $90 \%$ - is achievable with such an arrangement. Such devices will only rectify when the body force is present, but will work with homogeneous media, and nonlinearities in the density state function are not a prerequisite.

Type II rectifiers do not require a body force but do require a structural asymmetry in the direction of the heat flow. A simple example of such a device might consist of two dissimilar materials joined together, e.g. quartz and glass, with different thermal conductivity response func- tions over the temperature region of interest. Quartz, for example, has an approximately linear thermal conductivity over the temperature range from $100 \mathrm{~K}$ to $400 \mathrm{~K}$, but the slope is negative [16]. The conductivity of glass, on the other hand, has a positive slope over the same temperature range [17]. Simulations indicate that it should be possible to obtain a $20 \%$ rectification for $T_{\mathrm{h}}=350 \mathrm{~K}, T_{\mathrm{c}}=250 \mathrm{~K}$ with a quartz-glass composite device $(20 \mathrm{~cm}$ thickness of quartz jointed to $1 \mathrm{~cm}$ thickness of glass). It should be noted that nonlinearities in the response functions are not required for rectification to occur in this type of device (though clearly a nonlinear response function in one half of a composite device will give rise to rectification if the other component of the device behaves in a linear manner as a function of temperature). Examples of Type II thermal rectifiers which have been experimentally verified are the copper/cuprous-oxide junction device studied by Starr [3] and the expansion rectifier of Jones et al. [4]. The junction rectifier displays higher thermal conduction in the same direction as it displays higher electrical conduction (i.e. from the copper to the cuprous oxide), and the author therefore postulates that both are related to the behaviour of the free electrons. A rectification factor of $53 \%$ is estimated from the data provided in the paper [3]. The expansion rectifier relies on a nonlinearity in the rate of expansion of a stack of stainless-steel plates which are placed in contact with a solid block of aluminium. A rectification factor of $65 \%$ is reported for this device. Other Type II rectifiers listed in Table 1 have been proposed but they have not, to our knowledge, been experimentally verified (apart from the nanotube rectifier discussed in [20]).

Finally, there is a class of devices which combines both a body force and structural asymmetry; the water-saline diode discussed above falls into this hybrid category. Devices which exploit phase change materials (PCM's) would also belong to this hybrid group, as they rely on the activation of convection when one component of the composite system changes phase. Riffat et al. [18] discuss a heat pump which combines a thermal diode and thermoelectric modules; the device is asymmetric and relies on gravity for the diode effect and would therefore belong to the hybrid category.

Analogies may be drawn between heat flow and electrical current. The current rectifier (junction diode) is a passive device of fundamental importance in electrical and electronic engineering - it is to be expected that a heat rectifier would find many applications in thermal engineering. Unfortunately, heat diodes with high levels of rectification have proved elusive. The main device discussed here - the water-saline diode - is still well removed from what might constitute a useful heat diode: its $65 \%$ rectification does not compare favourably with rectification levels in excess of 99.99\% for current rectifiers (a typical 1 A PN junction diode has a maximum reverse bias current of the order of $50 \mu \mathrm{A}$ ). The dependence of the water-saline diode (and similar devices) on absolute temperature is also a limitation (the rectification factor of such devices goes to zero as the 
boundary temperatures shift away from the region encompassing the temperatures of density maxima). Nevertheless, the existence of any asymmetry in such simple devices, without the necessity of a phase change (and thus without any latent heat considerations) is potentially of interest. It is evident, for example, from the study of the water-perspex composite system, that heat flow asymmetries should occur in natural situations where bodies of cold water are adjacent to solid regions.

\section{Acknowledgements}

P.A. Mooney gratefully acknowledges support from the Irish Research Council for Science, Engineering and Technology.

\section{References}

[1] D.S. Lin, M.W. Nansteel, Natural convection heat transfer in a square enclosure containing water near its density maximum, Int. J. Heat Mass Transfer 30 (1987) 2319-2328.

[2] N. Seki, S. Fukusako, H. Inaba, Free convective heat transfer with density inversion in a confined rectangular vessel, Warme Stoffubertrag. 11 (1978) 145-156.

[3] C. Starr, The copper oxide rectifier, Physics 7 (1936) 15-19.

[4] A. Jones, P.W. O'Callaghan, S.D. Probert, Differential expansion thermal rectifier, J. Phys. E: Sci. Instrum. 4 (1971) 438-440.

[5] J.S. Moon, N. Keeler, A theoretical consideration of directional effects in heat flow at the interface of dissimilar metals, Int. J. Heat Mass Transfer 5 (1962) 967-971.

[6] M. Terraneo, M. Peyrard, G. Casati, Controlling the energy flow in nonlinear lattices: a model for a thermal rectifier, Phys. Rev. Lett. 88 (2002) 094302:1-094302:4.
[7] B. Li, L. Wang, G. Casati, ' Thermal diode: rectification of heat flux', Phys. Rev. Lett. 92 (2004) 254301:1-254301:4.

[8] D. Segal, A. Nitzan, Heat rectification in molecular junctions, J. Chem. Phys. 122 (2005) 194704:1-194704:12.

[9] D. Segal, A. Nitzan, Spin-boson thermal rectifier, Phys. Rev. Lett. 94 (2005) 034301:1-034301:4.

[10] M.F. Cawley, D. McGlynn, P.A. Mooney, Measurement of the temperature of density maximum of water solutions using a convective flow technique, Int. J. Heat Mass Transfer 49 (2006) 1763 1772 .

[11] M.F. Cawley, P. McBride, Flow visualization of free convection in a vertical cylinder of water in the vicinity of the density maximum, Int. J. Heat Mass Transfer 47 (2004) 1175-1186.

[12] Standard Test Method for Thermal Conductivity of Solids by means of the Guarded-Comparative-Longitudinal Heat Flow Technique, E 1225-87, Annual Book of ASTM Standards, 14.02, ASTM, 1994.

[13] A.J. Slifka, Thermal-conductivity apparatus for steady-state, comparative measurement of ceramic coatings, J. Res. Natl. Inst. Stand. Technol. 105 (2000) 591-605.

[14] Comsol Multiphysics, Comsol Ltd., London. <www.comsol.com>.

[15] R.C. Weast, M.J. Astle, W.H. Beyer (Eds.), Handbook of Chemistry and Physics, 65th ed., CRC Press, Boca Raton, FL, 1984.

[16] M. Sprackling, Thermal Physics, MacMillan Physical Science Series, UK, 1991

[17] D.G. Cahill, R.O. Pohl, Thermal conductivity of amorphous solids above the plateau, Phys. Rev. B 35 (1987) 4067-4073.

[18] S.B. Riffat, X. Ma, R. Wilson, Performance simulation and experimental testing of a novel thermoelectric heat pump system, Appl. Thermal Eng. 26 (2006) 494-501.

[19] V.A.F. Costa, M.S.A. Oliveira, A.C.M. Sousa, Laminar natural convection in a vertical stack of parallelogrammic partial enclosures with variable geometry, Int. J. Heat Mass Transfer 48 (2005) 779-792.

[20] C.W. Chang, D. Okawa, A. Majumdar, A. Zettl, Solid-state Thermal Rectifier, Science 314 (2006) 1121-1124. 